\title{
The Path Analysis to Increase Rural Income of Heilongjiang Peasant - the View of Transfer of Surplus Labor Force
}

\author{
Song ShuLi \\ School of Economic Management, Heilongjiang Bayi Agricultural University, Daqing ,China,163319
}

Keywords: Rural, Partial Least Squares, Transfer of Surplus Labor Force, Rural Income

\begin{abstract}
Based on the view of increasing rural income by transfer of surplus labor force, this study took partial elements as independent variable to build partial least-squares regression (PLS) model. According to the statistic data from 2003 to 2017 in Heilongjiang province, we analyzed the prechose variable about route of rural income increased by PLS method using matab 7.0 to analysis the data. The research suggested that all chosen variables have positive effect, such as value of agriculture production, value of forestry animal husbandry and fishery, number of rural workers, number of rural migrant workers, the total power of agricultural machinery, agricultural production investment, non-agricultural income and rural per capita net income. Based on analysis of result, this study proposed the effective transfer of surplus of labor force is the policy suggestion for realizing rapid growth in rural income.
\end{abstract}

\section{Introduction}

China is a typical country with surplus labor force. The 'Three agriculture-related issues' is the most prominent problem during the process of modernization and coordinated development of urban-rural economy. However, the core to solve the 'Three agriculture-related issues' is to solve the issue of increasing the rural income well. Based on the No.1 document of central government in year 2017, China will be rich in the near future, and farmer must be rich. To increase the rural income, it must promote farmer transfer employment and entrepreneurship. Heilongjiang is a big agricultural province which has 31 cities, 19 county-level cities, 46 counties and 459 towns. At the same time, it is also a populous province which owns a permanent population of 38.34 million, one of the which agriculture population of 16.678 million accounts for about $43.50 \%$ of the total population. In recent years, influences by natural conditions, an economic factor, social conditions and agricultural mechanization lead to a decline of the demand for labor in the agricultural production rapidly and producing a large number of surplus labor forces. About 9.486 million rural labor forces and 5.374 million people engaged in production of agricultural labor force and about 4.112 million rural surplus labor need to be transferred in the future. 
Domestic research showed that rural poverty problem must take reduction rural labor as the main strategic objectives ${ }^{[1]}$. Transferring rural surplus labor could promote to increase rural family income $^{[2]}$, at the same time, it could also narrow the rural income gap ${ }^{[3]}$, where may exist nonlinear relationship ${ }^{[4]}$, which is the precondition of food production scale ${ }^{[5]}$ and has become a new growth point of underdeveloped rural areas' income ${ }^{[6]}$.It has a positive correlation between farmers' income and the number of labor force engaged in the secondary industry ${ }^{[7]}$. Therefore, transfer of the rural labor could inhibit the expansion of urban-rural income gap in short time but it may cause the income gap expansion between urban and rural areas for the long run ${ }^{[8]}$. It showed that transfer of labor interacts with the income gap between urban and rural areas ${ }^{[9]}$, The discrimination for labor market in big city for the rural labor migration didn't really narrow the gap between urban and rural income $^{[10]}$. The degree of transferring rural labor force makes an important contribution to society economic development, while it also brings the negative impact on development of agricultural production $^{[11]}$. For example, a large number of transferring rural labor would make the land derelict, which woud be serious detrimental to agricultural sustainable development, and even affect food security $^{[12]}$. The growth of non-agricultural income from transfer of surplus labor has a strong periodicity $^{[13]}$. The importance of agricultural income from the income of farmers is gradually weakened, while the importance of non-agricultural income from the income of farmers is increased $^{[14]}$.

Through the literature review, it was found that more studies are qualitative research on the relationship between surplus labor transfer and farmers' income, and most of them are intuition judgment and general description, while relatively few systematic research are from a quantitative view. In addition, many of them are from national macro-level, and less research on micro-level of single provinces and cities, where especially the study of Heilongjiang province is quite few. Therefore, based on the perspective of surplus labor transfer, PLS model is adopted to analyze way of increasing farmers' income for Heilongjiang province, in order to verify the ideas and judgment that transfer of rural surplus labor smoothly and orderly is the most effective way of increasing farmers' income.

\section{Model Built and Analysis}

\subsection{Variables and Variable Description}

Peasant income consists of agriculture part and non-agriculture part. According to the impact factors of these two parts, it combined income source with components of Heilongjiang province peasant, According to expert's point of view who is devoted to research transfer of surplus labor force and peasant income, it was selected parts of variable as researching index( refer to Table 1)

\subsection{Principle of Model}

We assumed $y$ as dependent variable, $\mathrm{p}\left\{\mathrm{x}_{1}, \mathrm{x}_{2}, \ldots \mathrm{x}_{\mathrm{p}}\right\}$ as Independent variable, $\mathrm{n}$ as sample quantities, and $\mathrm{X}=\left[\mathrm{x}_{1}, \mathrm{x}_{2}, \ldots \mathrm{x}_{\mathrm{p}}\right]_{\mathrm{n} \times \mathrm{p}}$ as independent variable and $\mathrm{Y}=[\mathrm{y}]_{\mathrm{n} \times 1}$ as dependent variable For the requirement of regression analysis as extracting components , the two conditions shall be met as follows: 
Table 1: Variable and variable declaration

\begin{tabular}{|c|c|c|c|c|}
\hline Variable type & Variable symbol & Variable name & Unit & Variable description \\
\hline $\begin{array}{l}\text { Dependent } \\
\text { variable }\end{array}$ & $\mathrm{y}$ & $\begin{array}{l}\text { Rural per capita net } \\
\text { income }\end{array}$ & Yuan & From Statistical yearbook indicators \\
\hline \multirow{7}{*}{$\begin{array}{l}\text { Independent } \\
\text { variable }\end{array}$} & $\mathrm{X}_{1}$ & Agriculture output & $\begin{array}{l}\text { Ten Thousand } \\
\text { Yuan }\end{array}$ & Total value- Agriculture output \\
\hline & $\mathrm{X}_{2}$ & $\begin{array}{l}\text { Forestry and fishery } \\
\text { output }\end{array}$ & $\begin{array}{l}\text { Ten Thousand } \\
\text { Yuan }\end{array}$ & Total valu- Forestry and fishery output \\
\hline & $\mathrm{X}_{3}$ & $\begin{array}{l}\text { The number of people } \\
\text { entering farming }\end{array}$ & $\begin{array}{l}\text { Ten Thousand } \\
\text { Person }\end{array}$ & $\begin{array}{l}\text { The number of people performing farming at current } \\
\text { year }\end{array}$ \\
\hline & $\mathrm{X}_{4}$ & $\begin{array}{l}\text { The number of rural } \\
\text { migrant workers }\end{array}$ & $\begin{array}{l}\text { Ten Thousand } \\
\text { Person }\end{array}$ & $\begin{array}{c}\text { Rural labor force leaving countryside and living on } \\
\text { wage income }\end{array}$ \\
\hline & $\mathrm{X}_{5}$ & $\begin{array}{c}\text { Total power of } \\
\text { agricultural machinary }\end{array}$ & $\begin{array}{l}\text { Ten Tousand } \\
\text { KW }\end{array}$ & From Statistical yearbook indicators \\
\hline & $\mathrm{X}_{6}$ & $\begin{array}{l}\text { Agricultural production } \\
\text { investment }\end{array}$ & Yuan & Original value of fixed assets per capita \\
\hline & $\mathrm{X}_{7}$ & $\begin{array}{c}\text { The average } \\
\text { non-agricultural income } \\
\text { per capita }\end{array}$ & Yuan & $\begin{array}{l}\text { Rural migrant workers income in the employ of } \\
\text { enterprise or individual household, based on wage } \\
\text { income of statistical yearbook }\end{array}$ \\
\hline
\end{tabular}

Data source: 《Heilongjiang province statistical yearbook 2004-2018》, 《China Statistical Yearbook 2004-2018》, Derived from official website of Heilongjiang Statistic bureau directly or calculation.

1) $t_{1}, u_{1}$ shall possess variability information from their datasheet as much as possible.

2) The correlation of $t_{1}$ and $u_{1}$ shall reach maximum.

After extracting $t_{1}, u_{1}$, we performed the regression of $X v t_{1}$ and $Y v v_{1}$ by the method of PLS. If the regression equation get a satisfied accuracy, and the operation be terminated, otherwise we will perform the second operation using residual $\mathrm{X}, \mathrm{Y}$ to be resolved by $\mathrm{t}_{1}$. Looping computing fuction until we get the satisfied accuracy. Assuming components $t_{1}, t_{2}, \ldots t_{m}$ were extracted for $X$, we performed the regression of $Y$ to $t_{1}, t_{2}, \ldots t_{m}$ by PLS and then established regression equation of $Y$ to $t_{1}, t_{2}, \ldots t_{m}$, until PLS modeling is finished. Data matrix from normalization $X$ be marked $E_{0}=\left(E_{01}, E_{02}, \ldots E_{0 q}\right)_{n \times p}$, Data matrix from normalization $y$ be marked $F_{0}=\left(F_{01}, F_{02}, \ldots F_{0 q}\right)_{n \times p}$, The correlation of $\mathrm{t}_{1}$ and $\mathrm{u}_{\mathrm{i}} r_{i}=\frac{F_{0}^{\prime} t_{i}}{\left\|t_{i}\right\|}$.

When performing cross validation test, we made $Q_{h}{ }^{2} \geq\left(1-0.95^{2}\right)=0.0975$ as effective index, which showed that added component is valid to improve modeling quality, otherwise not(Wang huiwen, Wu zaibin etc. 2006). 


\subsection{PLS Analysis}

\subsubsection{Data Statistics, Multiple Correlation Test and Data Normalization Processing}

This paper collected Time-series data influencing rural income from 《Heilongjiang province statistical yearbook》, 《China Statistical Yearbook》2004-2018, multiple correlation test use Variance Inflating Factor. Variance Inflating Factor for $\mathrm{x}_{\mathrm{j}}$ is marked $\mathrm{VIF}_{\mathrm{j}}$, the calculation is $\mathrm{VIF}_{\mathrm{j}}=\left(1-\mathrm{R}_{\mathrm{j}}{ }^{2}\right)^{-1}$. Here $\mathrm{R}_{\mathrm{j}}{ }^{2}$ is the coefficient of multiple determination that regress $\mathrm{x}_{\mathrm{j}}$ to other independent variable. The maximum $\mathrm{VIF}_{\mathrm{j}}$ of $\mathrm{x}_{\mathrm{j}}$ is used as the indicator tesing multiple correlation. Generally, if $\mathrm{VIF}_{\mathrm{j}}$ is greater than 10 , which demonstrates $\mathrm{R}_{\mathrm{j}}{ }^{2}>0.9$ and multiple correlation will influence estimated value of LS(Least squares) seriously. Here can justify this independent variable is the approximate linear combination of other independent variable, independent variable and dependent variable are highly coorrelated. Using maltab7.0 to make the analysis to original data, this study showed correlation information of between variables are as follows( Table 2):

Table 2: Correlation factor between variables

\begin{tabular}{|c|c|c|c|c|c|c|c|c|}
\hline & $\mathrm{X}_{1}$ & $\mathrm{X}_{2}$ & $\mathrm{X}_{3}$ & $\mathrm{X}_{4}$ & $\mathrm{X}_{5}$ & $\mathrm{X}_{6}$ & $\mathrm{X}_{7}$ & $\mathrm{y}$ \\
\hline $\mathrm{X}_{1}$ & 1 & 0.9726 & -0.7715 & 0.8271 & 0.9708 & 0.9674 & 0.9868 & 0.9888 \\
\hline $\mathrm{X}_{2}$ & 0.9726 & 1 & -0.8541 & 0.916 & 0.9928 & 0.975 & 0.987 & 0.9922 \\
\hline $\mathrm{X}_{3}$ & -0.7715 & -0.8541 & 1 & -0.9774 & -0.8566 & -0.7868 & -0.7941 & 0.8057 \\
\hline $\mathrm{X}_{4}$ & 0.8271 & 0.916 & -0.9774 & 1 & 0.9125 & 0.8479 & 0.8573 & 0.8707 \\
\hline $\mathrm{X}_{5}$ & 0.9708 & 0.9928 & -0.8566 & 0.9125 & 1 & 0.9673 & 0.9907 & 0.9906 \\
\hline $\mathrm{X}_{6}$ & 0.9674 & 0.975 & -0.7868 & 0.8479 & 0.9673 & 1 & 0.9796 & 0.983 \\
\hline $\mathrm{X}_{7}$ & 0.9868 & 0.987 & -0.7941 & 0.8573 & 0.9907 & 0.9796 & 1 & 0.9973 \\
\hline $\mathrm{y}$ & 0.9888 & 0.9922 & 0.8057 & 0.8707 & 0.9906 & 0.983 & 0.9973 & 1 \\
\hline
\end{tabular}

Table 2 showed serious multiple correlations are existed both among dependent variables and among independent variables.

In order to remove adverse effects due to differences between test units and ensuring eaching variable own the same expression, we used maltab7.0 to make normalization treatment for dependent variables and independent variables and got normalization data as follows(Table 3):

\section{Extracting Principal Component}

1). Extracting the first principal component:

$$
\begin{aligned}
& \mathrm{W}_{1}{ }^{*}=(-0.3936,-0.3949,-0.3466,0.3207,-0.3943,-0.3912,-0.3970) \\
& \mathrm{P}_{1}=(-0.3804,-0.3911,-0.3673,0.3490,-0.3907,-0.3818,-0.3860) \\
& \mathrm{t}_{1}=\mathrm{E}_{0} \mathrm{~W}_{1}{ }^{*}=-0.3936 \mathrm{E}_{1}-0.3949 \mathrm{E}_{2}-0.3466 \mathrm{E}_{3}+0.3207 \mathrm{E}_{4}-0.3943 \mathrm{E}_{5}-0.3912 \mathrm{E}_{6}-0.3970 \mathrm{E}_{7}
\end{aligned}
$$

Regression Equation $\mathrm{F}_{0}$ to $\mathrm{t}_{1}$ :

$\mathrm{F}_{0} \quad \mathrm{r}_{1} \mathrm{t}_{1}=-0.3878 \mathrm{t}_{1}=0.1526 \mathrm{E}_{1}+0.1531 \mathrm{E}_{2}+0.1344 \mathrm{E}_{3}-0.1244 \mathrm{E}_{4}+0.1529 \mathrm{E}_{5}+0.1517 \mathrm{E}_{6}+0.1540 \mathrm{E}_{7} \quad$ (1) Cross validation judgement:

$\mathrm{Q}_{1}{ }^{2}=0.9576>\left(1-0.95^{2}\right)=0.0975$, it was demonstrated that adding component is valid to improve modeling quality and continue to extract principal component.

2). Extracting the second principal component: 
$\mathrm{W}_{2}{ }^{*}=(0.3251,0.0956,-0.5096,0.6990,0.0899,0.2351,0.2711)$

$\mathrm{P}_{2}=(0.3228,0.0849,0.5238,-0.4849,0.0815,0.2628,0.2662)$

$\mathrm{t}_{2}=\mathrm{E}_{0} \mathrm{~W}_{2}{ }^{*}=0.3251 \mathrm{E}_{1}+0.0956 \mathrm{E}_{2}-0.5096 \mathrm{E}_{3}+0.6990 \mathrm{E}_{4}+0.0899 \mathrm{E}_{5}+0.2351 \mathrm{E}_{6}+0.2711 \mathrm{E}_{7}$

Regression Equation $\mathrm{F}_{0}$ to $\mathrm{t}_{1}, \mathrm{t}_{2}$ :

$\mathrm{F}_{0}=\mathrm{r}_{1} \mathrm{t}_{1}+\mathrm{r}_{2} \mathrm{t}_{2}=-0.3878 \mathrm{t}_{1}+0.2354 \mathrm{t}_{2}$

$=0.2291 \mathrm{E}_{1}+0.1756 \mathrm{E}_{2}+0.0144 \mathrm{E}_{3}+0.2889 \mathrm{E}_{4}+0.1739 \mathrm{E}_{5}+0.2070 \mathrm{E}_{6}+0.2178 \mathrm{E}_{7}$

(2) Cross validation judgement:

$\mathrm{Q}_{2}{ }^{2}=0.2341>\left(1-0.95^{2}\right)=0.0975$, which demonstrate added component is valid to improve modeling quality and continue to extract principal component.

3). Extracting the third principal component

$\mathrm{W}_{3}{ }^{*}=(0.0634,0.2894,0.3812,0.3790,0.2261,-0.7448,0.1322)$

$\mathrm{P}_{3}=(0.0807,0.2279,0.2742,0.2935,0.3423,-0.8214,0.1654)$

$\mathrm{t}_{3}=\mathrm{E}_{0} \mathrm{~W}_{3}{ }^{*}=0.0634 \mathrm{E}_{1}+0.2894 \mathrm{E}_{2}+0.3812 \mathrm{E}_{3}+0.3790 \mathrm{E}_{4}+0.2261 \mathrm{E}_{5}-0.7448 \mathrm{E}_{6}+0.1322 \mathrm{E}_{7}$

(3) Cross validation judgement:

$\mathrm{Q}_{3}{ }^{2}=-0.4573<\left(1-0.95^{2}\right)=0.0975$, it was demonstrated that added component is not valid to improve modeling quality and terminate extracting principal component.

Table 3: Normalization scale data for variables.

\begin{tabular}{|c|c|c|c|c|c|c|c|}
\hline $\mathrm{X}_{1}$ & $\mathrm{X}_{2}$ & $\mathrm{X}_{3}$ & $\mathrm{X}_{4}$ & $\mathrm{X}_{5}$ & $\mathrm{X}_{6}$ & $\mathrm{X} 7$ & $\mathrm{y}$ \\
\hline-0.9458 & -1.1878 & 1.6004 & -1.7613 & -1.1097 & -1.1054 & -0.9507 & -1.0183 \\
\hline-0.8973 & -1.092 & 1.5798 & -1.4459 & -1.0791 & -0.8015 & -0.9165 & -0.9649 \\
\hline-0.8478 & -1.0366 & 1.5248 & -1.3251 & -0.9961 & -0.919 & -0.8824 & -0.9144 \\
\hline-0.8271 & -0.822 & 0.8987 & -0.8352 & -0.9377 & -0.8015 & -0.8513 & -0.8724 \\
\hline-0.6698 & -0.5989 & 0.2727 & -0.3033 & -0.8095 & -0.7327 & -0.8178 & -0.672 \\
\hline-0.5379 & -0.4845 & -0.0506 & -0.0315 & -0.5595 & -0.5857 & -0.7272 & -0.5847 \\
\hline-0.4053 & -0.4887 & -0.2948 & -0.0097 & -0.2609 & -0.4124 & -0.39 & -0.451 \\
\hline-0.1983 & -0.1899 & -0.7936 & 0.3191 & -0.0704 & -0.1525 & -0.1795 & -0.2167 \\
\hline 0.0316 & 0.2943 & -0.6938 & 0.554 & 0.1364 & 0.1357 & 0.0733 & 0.0759 \\
\hline 0.1167 & 0.418 & -0.484 & 0.6513 & 0.4761 & 0.0775 & 0.2552 & 0.2177 \\
\hline 0.3345 & 0.6545 & -0.711 & 0.95 & 0.7732 & 0.2587 & 0.648 & 0.6234 \\
\hline 0.9145 & 1.145 & -0.7042 & 0.9433 & 1.0939 & 1.5613 & 1.0989 & 1.1809 \\
\hline 1.6035 & 1.5591 & -1.0619 & 1.106 & 1.4945 & 1.7364 & 1.6656 & 1.5902 \\
\hline 2.3285 & 1.8294 & -1.0825 & 1.1882 & 1.8488 & 1.741 & 1.9745 & 2.0064 \\
\hline
\end{tabular}

\section{Extracting Principal Component}

1). Extracting the first principal component:

$\mathrm{W}_{1}{ }^{*}=(-0.3936,-0.3949,-0.3466,0.3207,-0.3943,-0.3912,-0.3970)$

$\mathrm{P}_{1}=(-0.3804,-0.3911,-0.3673,0.3490,-0.3907,-0.3818,-0.3860)$

$\mathrm{t}_{1}=\mathrm{E}_{0} \mathrm{~W}_{1}{ }^{*}=-0.3936 \mathrm{E}_{1}-0.3949 \mathrm{E}_{2}-0.3466 \mathrm{E}_{3}+0.3207 \mathrm{E}_{4}-0.3943 \mathrm{E}_{5}-0.3912 \mathrm{E}_{6}-0.3970 \mathrm{E}_{7}$ 
Regression Equation $\mathrm{F}_{0}$ to $\mathrm{t}_{1}$ :

$\mathrm{F}_{0}=\mathrm{r}_{1} \mathrm{t}_{1}=-0.3878 \mathrm{t}_{1}=0.1526 \mathrm{E}_{1}+0.1531 \mathrm{E}_{2}+0.1344 \mathrm{E}_{3}-0.1244 \mathrm{E}_{4}+0.1529 \mathrm{E}_{5}+0.1517 \mathrm{E}_{6}+0.1540 \mathrm{E}_{7} \quad$ (1) Cross validation judgement:

$\mathrm{Q}_{1}{ }^{2}=0.9576>\left(1-0.95^{2}\right)=0.0975$, it was demonstrated that adding component is valid to improve modeling quality and continue to extract principal component.

2). Extracting the second principal component:

$\mathrm{W}_{2}{ }^{*}=(0.3251,0.0956,-0.5096,0.6990,0.0899,0.2351,0.2711)$

$\mathrm{P}_{2}=(0.3228,0.0849,0.5238,-0.4849,0.0815,0.2628,0.2662)$

$\mathrm{t}_{2}=\mathrm{E}_{0} \mathrm{~W}_{2}{ }^{*}=0.3251 \mathrm{E}_{1}+0.0956 \mathrm{E}_{2}-0.5096 \mathrm{E}_{3}+0.6990 \mathrm{E}_{4}+0.0899 \mathrm{E}_{5}+0.2351 \mathrm{E}_{6}+0.2711 \mathrm{E}_{7}$

Regression Equation $\mathrm{F}_{0}$ to $\mathrm{t}_{1}, \mathrm{t}_{2}$ :

$\mathrm{F}_{0}=\mathrm{r}_{1} \mathrm{t}_{1}+\mathrm{r}_{2} \mathrm{t}_{2}=-0.3878 \mathrm{t}_{1}+0.2354 \mathrm{t}_{2}$

$=0.2291 \mathrm{E}_{1}+0.1756 \mathrm{E}_{2}+0.0144 \mathrm{E}_{3}+0.2889 \mathrm{E}_{4}+0.1739 \mathrm{E}_{5}+0.2070 \mathrm{E}_{6}+0.2178 \mathrm{E}_{7}$

(2) Cross validation judgement:

$\mathrm{Q}_{2}{ }^{2}=0.2341>\left(1-0.95^{2}\right)=0.0975$, which demonstrate added component is valid to improve modeling quality and continue to extract principal component.

3). Extracting the third principal component

$\mathrm{W}_{3}{ }^{*}=(0.0634,0.2894,0.3812,0.3790,0.2261,-0.7448,0.1322)$

$\mathrm{P}_{3}=(0.0807,0.2279,0.2742,0.2935,0.3423,-0.8214,0.1654)$

$\mathrm{t}_{3}=\mathrm{E}_{0} \mathrm{~W}_{3}{ }^{*}=0.0634 \mathrm{E}_{1}+0.2894 \mathrm{E}_{2}+0.3812 \mathrm{E}_{3}+0.3790 \mathrm{E}_{4}+0.2261 \mathrm{E}_{5}-0.7448 \mathrm{E}_{6}+0.1322 \mathrm{E}_{7}$

(3) Cross validation judgement:

$\mathrm{Q}_{3}{ }^{2}=-0.4573<\left(1-0.95^{2}\right)=0.0975$, it was demonstrated that added component is not valid to improve modeling quality and terminate extracting principal component.

\section{Building PLS Regression Equation}

As above calculation and ratiocination showed, it is only to extract two principal components for satisfying modeling quality, and the regression equation for normalization variable as follows:

$$
\begin{aligned}
\mathrm{F}_{0} & =\mathrm{r}_{1} \mathrm{t}_{1}+\mathrm{r}_{2} \mathrm{t}_{2}=-0.3878 \mathrm{t}_{1}+0.2354 \mathrm{t}_{2} \\
& =0.2291 \mathrm{E}_{1}+0.1756 \mathrm{E}_{2}+0.0144 \mathrm{E}_{3}+0.2889 \mathrm{E}_{4}+0.1739 \mathrm{E}_{5}+0.2070 \mathrm{E}_{6}+0.2178 \mathrm{E}_{7}
\end{aligned}
$$

Regression equation $\mathrm{y}$ to $\mathrm{x}=\left\{\mathrm{x}_{1}, \mathrm{x}_{2}, \ldots, \mathrm{x}_{\mathrm{p}}\right\}$ :

$$
\mathrm{y}=0.8345 \mathrm{x}_{1}+0.8342 \mathrm{x}_{2}+6.4500 \mathrm{x}_{3}+10.6437 \mathrm{x}_{4}+0.1147 \mathrm{x}_{5}+0.0326 \mathrm{x}_{6}+1.6716 \mathrm{x}_{7}-8325.1270
$$

As we can see from the equation(4), that $x_{j}$ is negative to showed $x_{j}$ and $y$ are negative correlation, that $x_{j}$ is positive showed that $x_{j}$ and $y$ are positive correlation.

For $\mathrm{x}_{1}, \mathrm{x}_{2}, \mathrm{x}_{3}, \mathrm{x}_{4}, \mathrm{x}_{5}, \mathrm{x}_{6}, \mathrm{x}_{7}$, the degree of positive correlation in a descending order as $\mathrm{x}_{4}>\mathrm{x}_{3}>\mathrm{x}_{7}>\mathrm{x}_{1}>\mathrm{x}_{2}>\mathrm{x}_{5}>\mathrm{x}_{6}$, That $\mathrm{x}_{4}$ is maximum indicated $\mathrm{x}_{4}$ is the biggest influence for $\mathrm{y}$.

Table 4: Judgement result of cross validation

\begin{tabular}{|c|c|c|}
\hline Quantities of component & $Q_{h}{ }^{2}$ & Critical value \\
\hline 1 & 0.9576 & 0.0975 \\
2 & 0.2341 & 0.0975 \\
3 & -0.4753 & 0.0975 \\
\hline
\end{tabular}




\section{Results Analysis}

From the PLS model regression equation (3) and figure 1, it was concluded that each variable xj's has influence on per capita net income of farmers $y$ : through the establishment of the regression equation, it showed that the larger independent variable regression coefficient absolute value, and the greater this variable's influence on per capita net income of farmers. Among these, That regression coefficient of the number of rural migrant workers $\mathrm{x} 4$ is 10.6347 means every increase of 1 person in number of rural migrant workers, per capita net income of farmers will increase 10.6347 yuan; Regression coefficient of agricultural workers x3 is 6.4500 , which means that every increase of 1 person in agricultural workers, and per capita net income of farmers will increase 6.4500 yuan; Regression coefficient of non-agricultural accept $\mathrm{x} 7$ is 1.6716, which means that when the non-agricultural income increase 1 yuan, per capita net income of farmers will increase 1.6716 yuan; Regression coefficient agricultural production $\mathrm{x} 1$ is 0.8345 , which means per addition 1 yuan of agricultural output value, and per capita net income of farmers will increase 0.8345 yuan; Regression coefficient of output value forestry animal husbandry and fishery x2 is 0.8342 , which means per addition of 1 yuan in forestry animal husbandry and fishery, and per capita net income of farmers will increase 0.8342 yuan; Regression coefficient of total agricultural machinery power x5 is 0.1147 , which means per addition of $1 \mathrm{KWH}$ total agricultural machinery power, and per capita net income of farmers will increase 0.1147 yuan; Regression coefficient of agricultural investment x6 is 0.0362 , which means per addition of 1 yuan in agricultural production investment, and per capita net income of farmers will increase0.0362 yuan.

The results showed that the agricultural output value and value of forestry, animal husbandry and fishery have the same influence on per capita net income of farmers to some degree. The reason is that all output values should deduct production costs of farming, forestry, animal husbandry and fishery, then the farmers' income. Agricultural mechanization level and the investment of agricultural production both affect per capita net income of farmers, but the impact is not significant. Non-farm income plays obvious promoting effect on increasing of per capita net income of farmers. In this study, In order to emphasize the relationship between the surplus labor transfer and the farmers' income, we took non-agricultural income which only take salary income earned in the form of engaging in non-agricultural industries after labor transfer to work as an example. In fact, the farmers' income of non-agricultural income partly also include the incomes from operating of the second and third industry and property transfer income and so on, so when we took the salary income as example to explain the influence of non-agricultural income from per capita net income of the farmers, and there is also gearing effect by property income and transfer income of the, etc. together with salary income.

Among these, how much the number of migrant rural labor directly shows the transfer of rural surplus labor, and non-agricultural income is the manifestation of earned income by engaging in non-agricultural industries in form of wages after the rural surplus labor transfer. Therefore, the research results showed that with the improvement of modern agricultural mechanization, agricultural output value increased at the same time and also produced a large number of surplus labor force. Retention of surplus labor force in agriculture will cause a decline in agricultural labor productivity, so agricultural production is improving but it does not affect much on the increase in per capita net income of farmers. At the same time, in the context of fixed land acreage and 
improving degree of agricultural mechanization, the effect to promoting farmers' income by increasing the number of workers for the agricultural will be limited. Therefore, the reasonable allocation of quantity of agricultural workers and rural migrant workers will have great influence on per capita net income of farmers. Moreover, forestry, animal husbandry and fishery industry are labor-intensive industry, where its development also depends on the transfer of rural surplus labor from the agricultural production, i.e. Lin Muyu output value of forestry, animal husbandry and fishery industry influence on per capita net income of farmers based on the premise of rural surplus labor transfer. Therefore, in the final analysis, the reasonable transfer of rural surplus labor force will have great influence on increasing per capita net income of farmers.

\section{Model Fitting and Prediction}

From the analysis of the results and using PLS regression equation model (4) to calculate the fitting results of per capita net income of farmers in Heilongjiang province (took integer data, chosen 2001-2014 as the example, and took 2015 as the prediction value for model applications). Among them, prediction of 2015(11410 yuan) is the independent variable which is increased by 10\% based on 2014, For instance, it was calculated by PLS model equation as follows, the condition of the agricultural output value (\$31.419 million), the forestry, animal husbandry and fishery industry output value (\$19.547 million), agricultural workers (7.334 million), the number of rural migrant workers (3.587 million people), agricultural machinery total power (54.4357 million kw), agricultural production investment (\$33015.4) and non-agricultural income (2190.8).

\section{Conclusions and Suggestions}

Through previous results analysis, we can reach the following conclusions: (1) various influencing factors, such as agricultural production value $\mathrm{x} 1$, forestry, animal husbandry and fishery industry output value $\mathrm{x} 2$, agriculture workers $\mathrm{x} 3$, the number of rural migrant workers $\mathrm{x} 4$, total agricultural machinery power $\mathrm{x} 5$, farmers productive investment $\mathrm{x} 6$ and of non-agricultural income $\mathrm{x} 7$ will directly affect the per capita net income of farmers y. (2) the PLS method can effectively eliminate the multiple correlation among each variable, at the same time, the PLS model is also a preferable research method of analyzing the influence factors to quantitative prediction and farmers' income, which can fit result close the actual statistics, own less prediction errors, and higher the prediction accuracy. (3) Adoption the PLS model can make the results more intuitively and it accurately reflect the influence of various influence factors to farmers' income, according to this, it was found that the smoothly and orderly transfer of rural surplus labor is the realization of the effective ways to increase farmers' income. (4) on the basis of the limited planting land area, it allocates rationally the agricultural workforce and the proportion of the number of rural migrant workers, which further increases the non-agricultural income and improves output value of forestry, animal husbandry and fishery industry to realize per capita net income of farmers and effective way.

For increasing farmers' income, it combined with the present situation of the rural population in China and surplus labor transfer long-term characteristic, the following policy suggestions have been put forward: (1) To accurately position the government in the labor transfer work, actively promote institutional innovation, change from directly management to indirectly control the economic, unblock external environment of rural labor force transfer. (2) To improve the training 
ability of training institutions and government should strengthen the support to training institutions, and increase training for farmers to enhance working skills and cultural quality of rural labor force, therefore, to increase the comparative employment advantage during transfer of labor force, which creates conditions for the rural surplus labor transfer. (3) To guide the establishment of rural labor transfer institutions or organizations, it improves the rural labor transfer information service and gradually establish the coordinated development of urban and rural labor market. (4) To standard recruitment mechanism, it fully plays the positive role of labor management and supervision departments to protect the transfer of rural labor forces' rights and interests. (5) To vigorously support the development of township enterprises, accelerate the process of rural urbanization and provide more transfer of labor force non-agricultural jobs, increase the demand for rural surplus labor force.

\section{References}

[1] Wang HuiWen,Wu ZaiBin,Meng Jie. Linear and Nonlinear Method of Partial Least-squares Regression. Bei Jing: National Defence Industry Press, In September 2006.

[2] Deng NianWu, Xu Hui. A Single Dependent Variable Partial Least-squares Regression Model and its Application. Journal of Wuhan University, 2010(2):14-16.

[3] Li Heng. The Empirical Study of Migrant Workers to Promote Farmers' Income. Agricultural Economic Problems, 2016(7):23- 26.

[4] Duan Jun. The Income Effect and Causes of China's Rural Surplus Labor Transfer Research. Chongqing University, 2012.

[5] Wang HongTao,LiWei,Yu HaiXia. To Promote Rural Labor Transfer Effectively to Increase Farmers' Income. Agriculture and Technology, 2018(10):9-12.

[6] Guan YongBin. China's Rural Labor Transfer to the Farmers' Income Effect Research. Southwest Agricultural University, 2005.

[7] Song ShuLi, Qi WeiNa. Based on the Multiple Linear Regression of the Rural Surplus Labor Transfer Research. Agricultural Technology Economy, 2016(3):104-109.

[8] Lai XiaoLu. Study on the Relationship between the Agricultural Labor Force Transfer and Farmers' Income in Liaoning Province. Shenyang Agricultural University. 2006.

[9] Lin Yan.Variable Selection Method of Least Squares and its Application Research. Xiamen University, 2007.

[10] Gao MengKe. Rural Surplus Labor Transfer to Urban and Rural Residents Income Gap Analysis of the Effect. The Communist Party of China Journal of Sichuan Provincial Party School, 2014(4):51-55.

[11] Yu Jan. Based on PLS Regression Methods in the Study of the Application of the Economic System. Harbin Engineering University. 2018.

[12] Liu Anyuan. Heilongjiang Province Rural Surplus Labor Force Estimation and Prediction Research Problem. The Northeast Agricultural University, 2008.

[13] Gao ShiLiang, Wang XinYuan, Chen XiaoLi. From the Perspective of Sustainable Agricultural Development of rural surplus labor transfer. Economic manager, 2015(2): 8-10.

[14] Li Ai. The Government Behavior of Rural Labor Transfer. Jinan:Shandong People's Publishing House, In August 2016. 